\title{
The Historical Realization of the Americans With Disabilities Act on Athletes With Disabilities
}

\author{
Michael Cottingham, Michael Carroll, \\ Don Lee, Deborah Shapiro, and Brenda Pitts
}

\begin{abstract}
The Americans with Disabilities Act (ADA) of 1990 has been one of the most powerful tools used by persons with disabilities in the fight for access and equality. Significant case law demonstrates the impact of the ADA on disability sport participation and access, but little is known regarding how the ADA has impacted athletes with disabilities. Thus, the purpose of this study was to gain the perspective of elite athletes with disabilities who competed before and after the ADA's enactment. Participants were interviewed, and the data were transcribed and analyzed. Findings indicated that participants generally felt physical barriers were most problematic before the ADA and improved greatly after the ADA. Economic barriers, social barriers, and barriers of legitimacy were challenging to athletes before the ADA, but views differed on whether these issues improved and to what extent improvement occurred following the implementation of the ADA.
\end{abstract}

The Americans with Disabilities Act (ADA) of 1990 is generally regarded as the most important piece of federal legislation for people with disabilities ever passed and has reframed disability as a civil rights issue. Predecessor legislation such as the Rehabilitation Act of 1973 and the All Handicap Children's Act of 1975 addressed access to public buildings and access to education; however, their impacts were limited compared with the ADA. The breadth of the law addresses issues as employment, accessibility, public services, consumer access, transportation, and telecommunications. The ADA and its relatively recent amendments of 2008 with broadens the definition of disability represent the most significant legislation aimed at preventing discrimination against persons with disabilities. With legal protections, corresponding regulations, and the right to bring legal action when they are discriminated against due to their disability or disabilities in certain public contexts (Colker, 1999), the impact of the ADA cannot be understated.

The ADA has a rich history of use within the context of sport, from spectators seeking accommodations for game-viewing to athletes with disabilities seeking to participate and compete in a chosen sport. Swartz and Watermeyer (2008) note that athletes with physical disabilities, and in the case of the current study, those with

Cottingham (mcotting@central.uh.edu) and Lee are with the Dept. of Health and Human Performance, University of Houston. Carroll is with the College of Health and Human Services, Troy University. Shapiro and Pitts are with the College of Education, Georgia State University. 
physical disabilities, tend to be the de facto spokespeople related to disability, and their experiences are most visible to society. Athletes with physical disabilities have dual considerations related to how they experience disability. As athletes, they are more likely to deal with barriers in regards to extensive travel, event access, social support for their competitions, and numerous other considerations. They tend to take more forms of transportation, stay in more hotels, use recreation facilities, and interact with more people in social situations due to their public personae. Yet as individuals, they carry out their day to day lives and engage with their surrounding world as would any other person with a disability. For these reasons, this population of athletes with physical disabilities may share unique perspectives on the ADA and its impact on their individual experiences. Thus, the purpose of this study is to gain the perspective of elite athletes with disabilities who competed before and after the ADA began to impact access: specifically, they needed to begin competing in elite sports before 1990 and continue after 1995. This allowed us to explore the experience of being an athlete before the ADA and examine the changes that might have occurred post ADA. To assess the effectiveness of the law, elite athletes with physical disabilities were chosen to represent the study group for the aforementioned reasons as they were social leaders, used more services, engaged in public more, and had a unique position as an elite athlete and a person who experienced disability every day.

Participants were all elite athletes with disabilities who used wheelchairs and who performed competitively within the aforementioned timeframe. They were interviewed individually and asked probing questions on how the ADA impacted their experiences both as athletes and as persons with disabilities. The constant comparative method was used to analyze the data and assess the effectiveness of the milestone ADA legislation. To provide related context that led to the study, the following literature review will focus on disability sport and the ADA.

\section{Literature Review}

\section{The ADA and Disability Sport}

Disability Sport and Barriers. The research to date on the ADA has focused most frequently on employment and compliance rates and has been quantitative in nature. Physical disability is the primary focus of our research because we presumed the differences in sport experience might have been more readily noted by participants with physical disabilities as they would be impacted by financial and psychological barriers as those with cognitive or developmental disabilities might have but also by physical barriers. Barriers to disability sport participation are numerous and impactful. A review of literature identified three primary barriers faced by athletes with disabilities: (a) physical, (b) financial, and (c) psychological.

Physical Barriers. Substantive research on ADA disability has focused on access to sport from a nonparticipatory position (Grady \& Ohlin, 2009; Mestayer, Black, Edwards, Behlmann, \& Cottingham, 2013), physical access to sport and recreational services (Grady \& Andrew, 2002) and access to sport websites (Grady $\&$ Ohlin, 2004). However, while the ADA and other related legislation address physical barriers and access, individuals with disabilities still purport that physical 
constraints are a highly limiting factor related to exercise and sport (Meyers, Anderson, Miller, Shipp, \& Hoenig, 2002; Rimmer, Riley, Wang, Rauworth, \& Jurkowski, 2004). In addition, these barriers can provide a limiting experience both personally and professionally for those who use wheelchairs and do not participate in sport (McClain, Medrano, Marcum, \& Schukar, 2000). Perhaps the first and most basic of physical constraints is transportation. Due to transportation challenges, nonparticipation in physical activity is far too common for individuals with disabilities (French \& Hainsworth, 2001; Rimmer, 2005). If a facility is not within walking or rolling distance, and public transportation is not both available and reliable, then the participants must be economically capable of transporting themselves or have a willing friend or family member in a position to do so. For those without means for steady transportation, participation is simply not an option. In addition, if the facility is perceived as unmanageable due to physical barriers, participation is limited or participants are completely excluded.

Financial Barriers. The most common and challenging barrier for disability sport participation stems from economic limitations. Research demonstrates that persons with disabilities are underemployed (Jenkins \& Rigg, 2004), thus hindering their ability to cover expenses related to disability sport, including equipment, chairs, and adaptive accommodations (Rimmer et al., 2004). The cost of sport wheelchairs alone can limit sport participation both domestically and internationally (Authier, Pearlman, Allegretti, Rice, \& Cooper, 2007), and combined with the distance many athletes need to travel to access a team or compete, as well as the periodic need to fund support staff, disability sport is far more cost prohibitive for participants than it is for those in able-bodied sports.

Psychological Barriers. Finally and perhaps most interestingly, research shows that psychological barriers exist that limit disability sport participation. These barriers vary greatly from simple lack of motivation and insecurity about participation (Buffart, Westendorp, van den Berg-Emons, Stam, \& Roebroeck, 2009; Stephens, Neil, \& Smith, 2012) to perceived judgment by society that individuals with disability are not valued as athletes (Cottingham, Pate, \& Gearity, 2015; Hardin \& Hardin, 2004).

\section{The ADA and Case Law}

The numerous physical, financial, and psychological barriers faced by participants of disability sport are clearly evident, and one of the most overt ways they have been addressed is through legal action. One method of seeing the actual impact of the ADA is through analysis of case law occurring within the context of sport. As previously noted, the ADA was passed to protect the rights of person with disabilities and prevent discrimination. Within the sport industry, the ADA has most commonly been used in cases involving (a) stadium design, (b) competition rules, and (c) eligibility rules. The following cases exemplify some direct benefits resulting from the ADA in overcoming participation barriers.

At the youth sport level, a 9-year-old with cerebral palsy was barred from participating in his soccer league due to his use of a walker. League officials claimed it was a safety hazard, but the U.S. District Court judge found only a remote chance of injury due to the padded walker and thus ordered that he be allowed to participate with his team 
(Boyd, 1999). In Johnson v. Florida High School Activities Association (1995), a 19-yearold student brought suit against the FHSAA, alleging the Association's age requirement, which prevented him from participating in football and wrestling, violated the ADA, as he had been held back in school by cause of hearing impairments that occurred due to meningitis as an infant. The Association argued that it was an essential eligibility requirement and a safety issue, but the court ruled against the FHSAA, stating that safety and fairness would not be compromised by the waiver. Furthermore, waiving the age requirement did not fundamentally alter the nature or purpose of the program and was thus a reasonable accommodation for Johnson's disability.

A primary example o a facilities based case is Paralyzed Veterans of America v. D. C. Arena L.P. (1997), the plaintiffs brought suit against the owners of a professional sports arena for failing to provide seating with proper lines of sight for persons with disabilities, in violation of Title III of the ADA. The Appellate Court affirmed the lower court ruling that most but not all of the wheelchair-accessible seating needed to have sight lines that were clear even if persons in front of them were standing. The same organization settled a lawsuit in 2008 with the University of Michigan during its stadium renovation regarding the number of wheelchairaccessible seats, something stipulated by the ADA (Nelson, 2008).

PGA Tour v. Casey Martin (2001) represented the first application of the ADA in a professional sport context. Casey Martin, a professional golfer with a disability affecting his walking, was able to successfully challenge the Tour's "no cart" rule as a violation of the ADA by failing to make their tournament accessible to persons with disabilities. The Supreme Court first ruled that the Tour's golf courses constituted a place of public accommodation covered under Title III of the ADA; second, that allowing Martin the use of a cart did not provide him a competitive advantage over other players and thus the accommodation was reasonable. The limitations of the aforementioned studies are that they all focus on a post-ADA world. We have little to no documentation on what a pre-ADA world looks like and limited research with a first person presentation from the athletes' perspectives. Therefore, the purpose of this study is to examine the lived experiences of athletes who competed before and after the ADA and to examine their perspectives on whether they felt the law impacted them as athletes with physical disabilities and to what extent.

Two research questions directly guided the purpose of this paper:

1. What barriers did athletes face in years before the ADA?

2. Did these barriers diminish or evolve over time, and what, if any, role did the athletes feel the ADA played in these changes?

It should be noted that ancillary findings were identified during the analysis and were included in the results section.

\section{Methods}

\section{Participants}

Purposeful sampling was used to obtain information-rich sources of data (Patton, 2002). All participants were former elite athletes who use wheelchairs. As noted in the literature review, we selected athletes with physical disabilities because we 
believe they might have been impacted by more aspects of the ADA. We define elite athletes as meeting at least one of the following criteria: (a) they competed on a Paralympic team; (b) they competed in a team sport, they were a starter, and their team won a National Championship or finished runner up; or (c) they competed in an individual sport and were ranked in the top ten in the nation (or top 20 in world ranking) in their sport. In addition, the athletes had to compete before 1990 and after 1995. The impact of the ADA was presumably not immediate; therefore, we hope that those who competed during the 1980s and before and during the mid-1990s or after would have been in the best position to witness the true results of the ADA.

Participants were identified by several means. When possible, documents were identified through contact with disability sport governing bodies and through a review of back issues of Sports and Spokes Magazines that provided world and national rankings and results. Athletes were then contacted through social media and e-mail. Furthermore, online announcements were created and posted to wellknown social media and sporting websites to identify additional athletes. We used snowball sampling and word of mouth as well, and tried to gain representation from athletes of various sports and genders.

We asked a single selection question to determine participant mobility. Many wheelchair athletes ambulate with a mobility impairment when not competing. For example, they may wear a prosthesis if they are an amputee, or have an incomplete injury that allows them to walk with a limp. We wanted to interview athletes who did not ambulate as their primary noncompetition mode of propulsion to better assess the barriers experienced by those unable to ambulate over physical obstacles. Of those who agreed to participate in the current study, five were excluded due to being ambulatory the majority of the day.

In total, fifteen individuals participated in the study, representing athletes from wheelchair basketball, tennis, hand cycling, racing, field events, table tennis, and wheelchair rugby. Due to the evolving nature of wheelchair sports in its earlier years, some athletes may have competed in one sport for a period of time and then another, or been high level in one sport but elite in another. Table 1 indicates all participants' pseudonyms, what sport(s) they competed in at an elite level, their disability, and what year they began in disability sport. All participants were provided with a pseudonym to provide anonymity. That being said, we informed all participants that, due to the rather narrow sample pool we were drawing from, we could not guarantee anonymity.

\section{Data Collection}

Semistructured interviews were conducted with each participant, and all interview questions presented were related to the research questions (Anfara, Brown, \& Mangione, 2002). Our initial questions focused on experiences in the early points in the athletes' careers and then later in the athletes' careers. At times, probes were provided such as, "What was it like in the mid-90s?" After exploring these career periods, we asked specific questions related to the ADA. Because all participants executed a consent form that noted the ADA, those who diligently read the form were more primed to the ADA than others. Consequently, some participants answered questions with an ADA frame while others took a more general approach. Interestingly, this did not provide substantive differences in the results. 


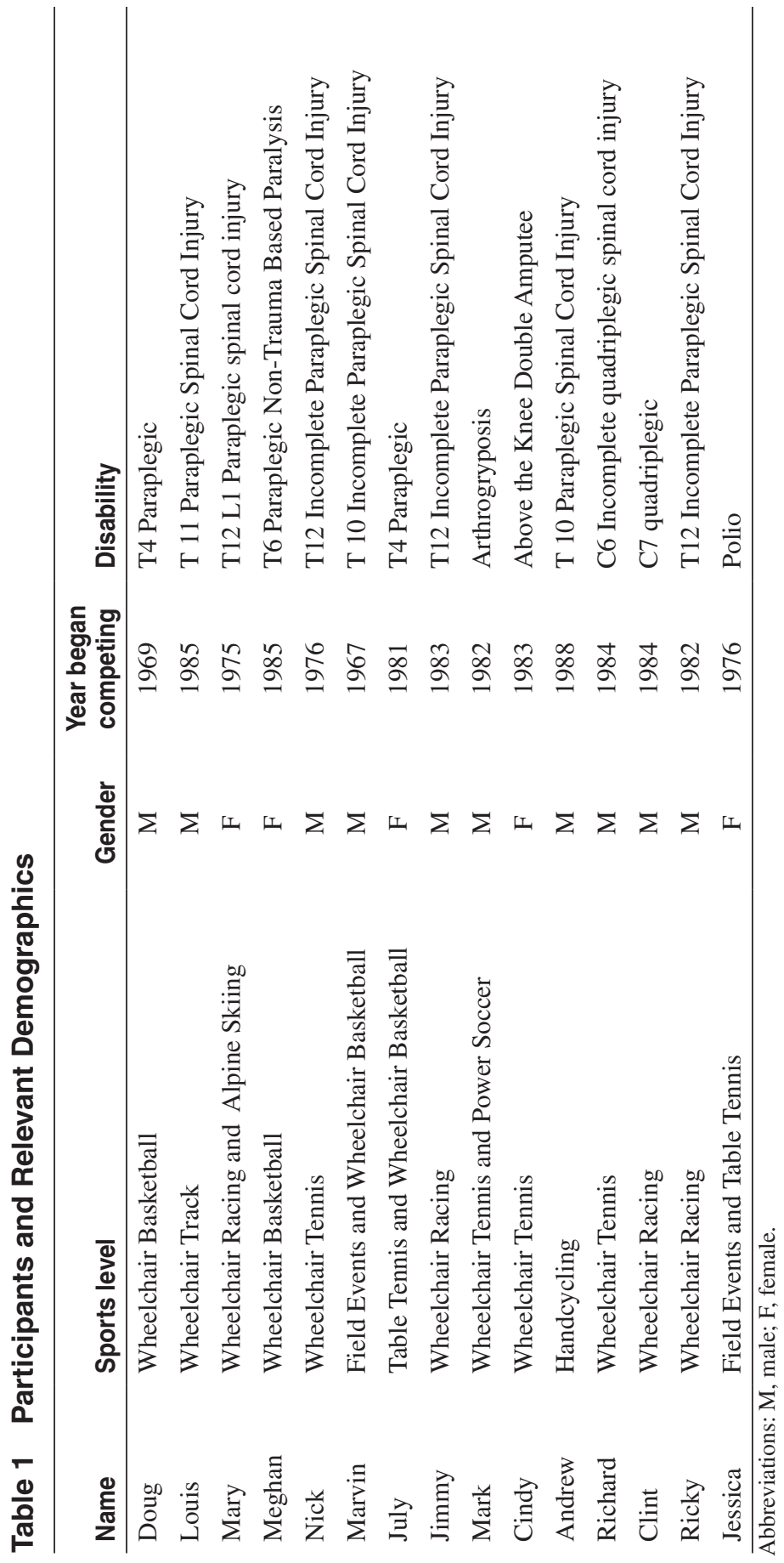


Example questions included:

- What was it like competing in the early years?

- Did your experiences change over time?

- What barriers impacted your participation?

- Did you notice any changes in these barriers over time?

- How might access have impacted your life as an athlete?

- In what ways do you feel the ADA impacted you as an athlete and a person with a disability?

- In what ways did the ADA impact the barriers you mentioned before?

All interviews were conducted over the phone or via Skype by the first author; they were audio recorded, and lasted between $32 \mathrm{~min}$ and one hour and $23 \mathrm{~min}$.

Data were analyzed using the constant comparative method (Charmaz, 2006; Strauss \& Corbin, 1998). This method is most appropriate when little is known about the topic. The primary investigator, who has completed formal education in qualitative research, read and coded each transcript individually, engaging in line by line analysis. This helped to identify themes and sub themes. After themes and subthemes were determined, authors selected exemplary quotes to summarize participant perspectives. Another institutional faculty member provided peer debriefing (Lincoln \& Guba, 1985).

\section{Results and Discussion}

The results and discussion have been combined to comprehensively examine the findings and their relationships to the literature and greater themes in the paper. Our research questions sought to identify barriers faced by athletes with disabilities before the ADA and how these barriers evolved over time after the establishment of the ADA. We have combined the presentation of these research questions into a single narrative so that the reader can explore barriers experienced by athletes, how those barriers evolved, and how the athletes felt those barriers were impacted by the ADA.

Participants broadly identified four themes: (1) physical barriers, (2) economic barriers, (3) social barriers, and (4) barriers of legitimacy that were most challenging in their pre-ADA athletic careers. These barriers were not dissimilar from the post-ADA barriers identified in the literature (and noted previously). However, as the analysis will demonstrate, the extent to which these barriers existed varied drastically. It should be noted that participants often intermingled the experiences they had as an athlete with those of their nonathletic persona; for example, they mentioned physical barriers limiting an everyday life experience that directly or indirectly may have impacted the athletic experience of the participant.

\section{Physical Barriers}

Not surprisingly, physical barriers were frequently cited as the most prominent barrier faced by athletes with disabilities. These barriers existed in contexts of day to day experiences, training, and in travel. Regarding the former, five 
participants described challenges related to everyday experiences that directly or indirectly impacted their lives as athletes. Several athletes explained that, as it took them more time to engage in everyday activities like going grocery shopping, they lost time and energy which could have been applied to athletic goals. As Doug shared:

When I wanted to go to the grocery store, and I live in a big city, I had to go to the loading dock and push in the back up the ramp where they loaded the food. Then I beat on the door till someone unlocked the door and let me in. I had to go through the frozen food section... and that's how I had to get groceries. Imagine any athlete going through that to get groceries.

In addition, seven of the participants specified physical barriers affecting their training, including access to acceptable practice and competition venues. Richard stated:

If you wanted to compete, and you were not in the city, you had to move somewhere enough guys lived. That way, you could all push and get one gym or tennis center set up where it was fully accessible. If you were isolated, you couldn't get facilities.

Interestingly, multiple athletes remarked that events and practices were most frequently held at universities. They also noted that universities were one of the only fully accessible athletic facilities they could regularly use. Basements of buildings were used for table tennis and new gyms were more accessible there than at other locations. None of the athletes connected this to the fact that the most sweeping disability accommodation legislation before the ADA was the Rehabilitation Act of 1973 which required, among other things, for all universities receiving public funding to provide accommodations for those with disabilities.

Finally, participants integrated everyday barriers in the context of travel, noting the most frequent issues were transportation to and from airport and venues, transportation to and from facilities, and hotel access. Cindy, who was discussing a time pre ADA when she was ranked 5th in the world in wheelchair tennis, offered:

Tournaments wouldn't have ..., they'd come pick you up. I've sat in the back on the floor of one of these workman vans? I'd sit on the floor with everyone piled up in that. That was our tournament transportation sometimes. You wouldn't even think of doing that nowadays because there's so many more opportunities with ramps and lifts.

Because of these challenges, those with more impactful disabilities like Clint, an incomplete quadriplegic, traveled with assistance:

Back then, usually I had couple of friends who were willing to ride along and spot me to get ready. I wasn't independent so much getting in and out of the chair, getting taped up and all of that. Plus, you never knew what you were going to experience at our hotels. Get there and . . . two steps to the door to the bathroom is like 18 inches wide. 
While recalling these physical barriers may have been amusing for these athletes, it was also clearly frustrating. Even when reflecting back 30 years, participants almost universally spoke with pride about how they overcame these challenges. Mary noted:

I like to say we were excellent adaptors at figuring out how to get in and out of bathtubs, how to get in and out of bathroom doors that were too small, as far as getting another chair that maybe was at the desk and setting that in the doorway, sitting on that and then hopping around the bathroom to try to get to the toilet and get into the bathtub.

Furthermore, multiple participants shared that learning how to address these barriers in conversations with other athletes created relationships. Mark explained:

Really some of the greatest friends I've ever met, the greatest people that I've ever met in the world and have developed friendships with, were out of that group. We learned from each other and that created a bond.

The aforementioned physical barriers were the same identified by Rimmer et al. (2004) as primary concerns that limit participation in physical activity for people with disabilities. That being said, the vivid and numerous descriptions we received make it clear that these barriers were far greater when these athletes began competing (1969-1984) than when Rimmer collected his data in a post ADA world. However, it is of interest to note not only how these physical barriers have changed over time, but also across geographical areas. For example, we see individuals with disabilities in Latin America experience these barriers to the same extent as those who lived and competed before the ADA took effect. As observed in our study by Latin American practitioners who are currently working in disability sport, athletes with disabilities in developing countries face a multitude of physical barriers as their countries lack much of the infrastructure and legal requirements needed to accommodate and support them (Cottingham, Blais, Bogle, Gearity, \& Zapalac, 2015).

Almost unanimously, participants noticed substantial improvements in addressing physical barriers from when they first began competing to their retirement and beyond. These included practice and competition facilities with ramps and doors wide enough to enter, accessible bathrooms at hotels and restaurants, transportation with lifts, and related services. As all of these participants competed before and after the ADA was in place (with some still recreationally competing), all with the exception of a single participant asserted that life as an athlete and as an individual with a disability involved far less physical barriers as the impact of the ADA was felt post-1990 and beyond. Their findings might seem to indicate less frustrations with physical barriers than those who do not participate in disability sport (McClain et al., 2000). When asked what additional changes they would like to see to advance accessibility, participants suggested having airplanes accommodate wheelchairs without using an aisle chair or having fully private handicap bathrooms; however, no substantive legislative recommendations were given. In this regard, Mary offered that physical barriers have so diminished through time and through her experience that she no longer notices them, but would need to interact in the world with new injuries to truly know whether more advancement would be necessary from a legal standpoint: 
If there are still physical barriers that are getting in my way, I am probably not even aware of them. I have been in a chair over 35 years. . . . I am probably unaware of them now, to see our next steps you might need to ask new injuries.

In addition, while the lion's share of credit in addressing these physical barriers was given to the ADA, due credit should also be given to durable medical supply manufacturers. Specifically, the improvements to wheelchairs has helped individuals overcome barriers more effectively and engage in society more confidently (more on this later). As Nick explained:

Pushing around a 60 pound wheelchair, the back of your shoulders were done, and then having the arm rails and the little handles at the back, it was so heavy ..., and you had breaks that hung out there that if you pushed them a certain way you would cut your thumbs off, you ended up cut up and bleeding. . . . You had to have a two door car to manage the chair. You'd fold that chair, throw it behind you in the seat, and you know it got all destroyed. Your house was destroyed because your chair was so long. The equipment is so much better now, and I'm not sure if that had anything to do with the ADA.

\section{Economic Barriers}

While economic barriers were not cited as frequently as physical barriers, the statements about the economic barriers were interesting because of the reflection that occurred to identify these as barriers, and also because of how interwoven economic barriers are with other barriers. For example, four participants expressed the difficulty in gaining employment and explained that at least part time employment was necessary to fund sport participation; however, it was the physical barriers that created difficulties or obstacles in achieving employment. Having acknowledged that reality, the most common concerns with economic issues were addressing expenses related to travel, coaching, and equipment. Both issues of personal employment and sporting expenses will be explored in light of the ADA. Multiple participants agreed that economic barriers improved over time, but debated about if these barriers had been removed or only mitigated. Cindy reported:

Back in '92 when I got my letter to go to the Paralympics, there was also a letter explaining how to fundraise, because now I had to come up with $\$ 1,500.00$ to go. Each athlete had to pay their way. Now ... we're treated like Olympians, I think equally_well, not equally_-but better, much better.

In contrast, Mary discussed how the movement for equality has stalled as athletes have not pushed for greater equality as aggressively in the last ten years. When discussing a contemporary able bodied racing series that did not provide prize money for athletes with disabilities, she said:

And I called out the athletes in wheelchairs. I said, "You guys don't have a wheelchair division in the World Marathon Group, and so you can't really claim that you're a World Marathon winner if you don't even have a division. And you should have a division, and you should be getting prize money. And I felt like they were really becoming complacent, were just like, "Oh, you know." 
It doesn't really do anything if we just let this stand, we have to keep pushing. And so by calling out these athletes, a couple of the athletes went forward and they lobbied for a position and a division within the World Marathon Group, and they have it now. And so that's why I say I think they're a little lazy.

The participants generally felt that the ADA did not directly impact the economics of funding their sports. However, theories emerged that the ADA addressed social barriers in that it helped create a society more culturally aware of disability and more supportive of disability sport. In this way, the ADA influenced social and physical barriers, and this, in turn, provided greater access to economic resources.

Concerning personal employment, the athletes were mixed when discussing the benefits of the ADA on assisting with this matter. Some elected to find traditional employment post competition (if they were not already working), while others found employment in the disability sport world (one of the few avenues of employment available to them before the ADA). Interestingly, two of those who found employment in nondisability contexts stated they had never previously considered their employment success was related to the ADA, but upon reflection, it might have greatly assisted them in being hired. Be that as it may, some literature implies that the ADA may have greater impact on employment for those with nonphysical disabilities rather than physical ones (Gouvier, Sytsma-Jordan, \& Mayville, 2003).

\section{Social Barriers}

The following sections have historically been seen as psychological barriers (Rimmer et al., 2004). We contend that this thinking stems from a medical model approach, or an idea that the disability is an individual's limitation rather than a societal barrier (Goering, 2002). The perspective of the participants in our study was that these barriers were primarily (but not exclusively) external. We have categorized these barriers into social barriers, or barriers which impact day to day social experiences, and barriers of legitimacy, or being perceived as an elite athlete in society. While these lines at times blurred, this distinction was quite clear in our participants' responses. On the contrary, there seemed to be no distinction at all when participants referred to themselves in an athletic context or an "everyday" context, as they freely and interchangeably switched back and forth between the two in their responses. We have simply drawn these distinctions for the sake of analysis.

Perceptions of the intensity of social barriers varied greatly depending on when participants started disability sport. Generally, the earlier the participants started disability sport, the greater the social barriers were felt. For those who competed at earlier points, several consistent themes and, more interestingly, consistent words, emerged. For example, participants first described they were seen as "aliens" when entering society and regarded as representatives of "Special Olympics" when discussing their athletics. The former was generally met with pride and amusement while the latter was met with offense. When discussing what it was like engaging with the community in the early 1970s, Marvin summed up the complexities of these experiences in a single quote:

They were amazed because at that time wheelchair people were considered as Special Olympics, is the easy way to say it ... people were afraid of you at that 
time, because there was two things - this is what my reasoning was anyway at that time. It was like they either thought that we were . . mentally retarded, or they were afraid of us because they see what could happen to their bodies. And so that's why they were real hesitant and reserved ... set back about us.

Yet the participants also felt gratified as they surprised the community with their unexpected abilities and showed they could publicly compete in athletics. As Mary explained:

When I first started competing, that we were looked at as, I like to say aliens. Or one of the things I used to say was, just being out on the street and wheeling by in my racing chair, training, go by people, and their heads would turn, their eyes would get big, and I would imagine them saying in their head, "What kind of animal was that?" because they'd just never seen anything like that.

Notably, social barriers were often intertwined with physical ones. Meghan reported:

I remember this one incident, clear as day 30 years later. There was a car completely parked on this ramp, and that meant the difference to class or not getting to class. I was just going to make it on time. I waited for him because I couldn't get to class and he came out. And I had this interaction with him, and he was like, "It's no big deal." "Well, no big deal for you. You can get around up steps fast!"

There was almost universal agreement that these social barriers improved over the years as well as social acceptance, but to what extent was a matter of debate. Meghan, for example, said, "They sort of fear you a little more in a good way, but they ... . don't always get it." She explained that the ADA helped people to understand there should be some consideration for people with disabilities and their needs. Others such as Nick felt that the modern world is much more accepting and engaging in society, and as Cindy struggled to recall, she seemed to agree, though with hesitation and a clear desire for more:

I think it's getting better, the way we are seen. It's a little better, a tiny bit better, no, it's a lot better. Well, the day that people don't see our chairs first would be the day that, yeah, we're there, but people just see the disability first still. They've gotten better, you know? They've become educated, but it's still there.

As her life in disability sport extended over such a long period of time, she had to reframe her perspective to realize that although lacking, the situation has indeed improved through the years. In addition, most of these athletes were and still are advocates for disability sport and access, so they viewed these social barriers through a number of lenses and various levels of expectation. Incidentally, the theme of a person with a disability not having their wheelchair seen, was frequent in our findings, with several athletes noting it was a valuable complement. This theme is not unique to our study as it was identified as a desire by many, but not all, people who use wheelchairs (Jongbloed \& Crichton, 1990).

Beyond the debate of social change, the greater controversy was how effectively the ADA addressed the social barriers. Two camps clearly emerged. The first 
was that the ADA had minimal impact on addressing social barriers, primarily by raising awareness. For example, Louis noted:

So I think the ADA has addressed some of those societal issues, from a standpoint of raising awareness sort of putting it back in front of people and keeping in their minds, but we already had some laws on the books before the ADA. I think its impact on addressing social views is overrated.

In contrast, other participants felt the ADA had a significantly greater impact on addressing social barriers through indirect means. Clint provided a succinct explanation of this:

I think it [ADA] definitely impacted the exposure just because it opened up so many more opportunity for people with disability just to go places and out in public .... When I was first injured and ran across somebody else in a wheelchair it was kind of a rare occurrence and now they're everywhere, having more people out there, having more interactions, positive or negative had to impact the perception of people with disabilities.

In other words, addressing the physical barriers helped create an environment where society had more exposure to disability, which, in turn, impacted perceptions.

The most unexpected theme that came up frequently on this question was the belief that the athletes themselves (as well as other disability activists) had played a part along with the ADA in addressing social barriers. Mary noted that the athletes were often seen as the pleasant likable side of disability:

I think the ADA is like a stick. I think it's like beating people over the head so they do the least amount they have to do to be able to accommodate and do what the law says to do. And people are not embracing the law as an opportunity. We are the carrots, so I don't know if this is actually a legal thing, and I don't think it really is. I think it really is a PR thing. And it really comes down to our stories, because if our stories are used in marketing, people see themselves in our stories. They see that connection; that is how you change social standing.

While Jim explained the importance of advocacy from a different perspective:

You know what changed things, it was people that came before me, like those crazy fuckers, what were they called, ADAPT? They tied themselves to busses and wouldn't move. They got arrested. That is how you get social standing, you show you can take some power.

\section{Barriers of Legitimacy}

While the social barriers were framed as micro experiences related to how a changing society perceived people and athletes with a disability, the barriers of legitimacy were macro issues more focused on the perception of the athlete in particular. Almost universally, these barriers were perceived as highly problematic and restricting. Experiences related to societal perceptions of individuals with disabilities as elite athletes were typically limiting. As Marvin stated: 
I guess you were kind of put on a back shelf, people would find out you did wheelchair basketball or I threw the javelin and shot archery, and they were just kind of like, "Yeah, yeah, yeah, this guy's just talking stories now."

These frustrations tied into economic and social barriers. Specifically, the athletes generally felt that being perceived as having mental disabilities as well as physical ones impacted their ability to be accepted as elite athletes. This, in turn, hindered their ability to acquire prize money and attract sponsors. As Andrew illustrated:

The prize money wasn't there, because they didn't see us as belonging. We were a sideshow at first, we were the Special Olympics, not that there is anything wrong with those guys but it's not who we are. As time went on, it got better, we got prize money and points and recognition.

These issues were complex as several participants recognized that these barriers of legitimacy likely stemmed from a position of social weakness. Marvin, who competed from the late 1960 s to the early 2000s, pointed out:

I guess people were prejudiced against us. It was like girls, blacks, and then gimps . . . that's how I think everybody felt about that. We just didn't belong on TV, not as athletes.

There was universal agreement among most of the participants that these barriers of legitimacy have improved substantially over the course of their careers. The most common allusions to this were greater exposure of the Paralympics, the efforts of able bodied sports organizations to accept and integrate disability sport, such as the International Tennis Federation, the United States Tennis Association, the United States Olympic Committee, and numerous marathons in incorporating athletes with disabilities, and additional television coverage. Two additional telling themes became evident in the participants' interviews. First, that there was no bitterness related to those who came later and received greater legitimacy than our participants, and second, that many participants felt modern athletes with disabilities had an obligation to not be content, but instead push for greater coverage. Andrew said:

Look ... now you can sometimes see wheelchairs sports . . . always on channel 532 at 2 AM but it's there. . . . . They just need to use their current platform to keep pushing. Keep performing and attracting attention and keep pushing for more.

Research seems to echo the athlete's perspectives; great strides have been made in media coverage, but they still lag behind what might be expected of elite international sports (Ellis, 2009; Howe, 2008; Pappous, Marcellini, \& de Léséleuc, 2011) and courts do not take into considerations the positon of athletes with disabilities when considering the application of the ADA on athletes with disabilities (Moorman \& Masteralexis, 2001).

When considering various types of barriers, those related to legitimacy were probably the most polarizing in terms of the participants' opinions regarding the impact of the ADA. To show differing stances, we examined Mary's comments highlighting the benefits of the ADA: 
I think the benefits of the ADA and the Judge Stevens Act is that athletes now are under USOC, US Paralympic banner, and when a Paralympic Games, Olympic Games come around and they have qualified, there is no financial responsibility on their part of the athletes whatsoever. And the endorsements that are available to high profile athletes in sports are strong, for some high profile like track and field and alpine skiing-they have immense amount of funding that's available for them to be able to support themselves, because most of us had to hold jobs down or pound the pavement ... that is a credit to the ADA.

Meanwhile, Doug remarked:

The ADA was a great start, it made people value us as people because it required accommodation. It does not make people value our achievements, just allows us to be seen as people. Those achievements are our credit.

\section{Conclusions and Future Research}

We feel that this unique study provides perspective on how wheelchair sports participants who competed before and after the ADA felt the law impacted them both inside as well as outside of sport. These findings showed that, in general, participants felt their lives had improved across multiple categories over time in both domains. Perspectives regarding the cause and degree of improvement varied between participants. Generally, athletes felt the ADA provided some direct and indirect benefit that improved their day to day lives, but factors such as self-advocacy, previously active advocates, better wheelchairs, and public recognition for athletic talents were also credited with impacting the athlete's experiences. We hope this research is valuable in the future. One way to possibly increase the insight gained from athletes from a study like this in the future would be to compare the athlete's experiences pre- and post- ADA. This perspective may enable authors in the future to interpret the perceived differences within the context of the ADA and may offer more informed speculation regarding the extent to which the ADA likely impacted the experience of athletes with disabilities. As times surpasses the establishment of ADA, the historical impact of the legislation and its impact on athletes will be more difficult to measure with firsthand accounts. We also hope this research is replicated with athletes with different impairments, including ambulatory mobility impairments, blind and deaf athletes, and those with neurological disabilities. In addition, other nations have addressed accommodations for disability with various legislation over time. Perhaps future research could examine whether similar experiences are faced by athletes currently in developing nations or with more recently implemented legal protections.

\section{References}

Anfara, V.A., Jr., Brown, K.M., \& Mangione, T.L. (2002). Qualitative analysis on stage: Making the research process more public. Educational Researcher, 31, 28-38. doi:10.3102/0013189X031007028 
Authier, E.L., Pearlman, J., Allegretti, A.L., Rice, I., \& Cooper, R.A. (2007). A sports wheelchair for low-income countries. Disability and Rehabilitation, 29(11-12), 963-967. doi:10.1080/09638280701240714

Boyd, D. (1999) Boy plays soccer with aid of walker. Retrieved July 23, 2015 from http:// www.apnewsarchive.com/1999/Boy-Plays-Soccer-With-Aid-of-Walker/id-980cefca9418b9e3cd4ff84c2552cd93.

Buffart, L.M., Westendorp, T., van den Berg-Emons, R.J., Stam, H.J., \& Roebroeck, M.E. (2009). Perceived barriers to and facilitators of physical activity in young adults with childhood-onset physical disabilities. Journal of Rehabilitation Medicine, 41(11), 881-885. doi:10.2340/16501977-0420

Charmaz, K. (2006). Constructing grounded theory: A practical guide through qualitative analysis. Thousand Oaks, CA: Sage.

Colker, R. (1999). Americans with Disabilities Act: A windfall for defendants. Harvard Civil Rights-Civil Liberties Law Review, 34, 98.

Cottingham M., Blais, D., Bogle, K., \& Gearity, B., \& Zapalac, R. (2015). A qualitative examination of Latin American wheelchair sport practitioner's marketing practices. Journal of Sport for Development, 3(5), 9-19.

Cottingham, M., Pate, J.R., \& Gearity, B. (2015). Examining "inspiration": Perspectives of stakeholders attending a power wheelchair soccer tournament. Canadian Journal of Disability Studies, 4(1), 59-88. doi:10.15353/cjds.v4i1.188

Ellis, K. (2009). Beyond the aww factor: Human interest profiles of Paralympians and the media navigation of physical difference and social stigma. Asia Pacific Media Educator, 19, 23-36.

French, D., \& Hainsworth, J. (2001). "There aren't any buses and the swimming pool is always cold!": Obstacles and opportunities in the provision of sport for disabled people. Managing Leisure, 6(1), 35-49. doi:10.1080/13606710010026359

Goering, S. (2002). Beyond the medical model? Disability, formal justice, and the exception for the "profoundly impaired.". Kennedy Institute of Ethics Journal, 12(4), 373-388. doi:10.1353/ken.2002.0025

Gouvier, W.D., Sytsma-Jordan, S., \& Mayville, S. (2003). Patterns of discrimination in hiring job applicants with disabilities: The role of disability type, job complexity, and public contact. Rehabilitation Psychology, 48(3), 175-181. doi:10.1037/0090-5550.48.3.175

Grady, J., \& Andrew, D. (2002). Legal implications of the Americans with Disabilities Act on recreation services: Changing guidelines, structures, and attitudes in accommodating guests with disabilities. Journal of Legal Aspects Sport, 13, 231-252.

Grady, J., \& Ohlin, J.B. (2009). Equal access to hospitality services for guests with mobility impairments under the Americans with Disabilities Act: Implications for the hospitality industry. International Journal of Hospitality Management, 28(1), 161-169. doi:10.1016/j.ijhm.2008.06.013

Grady, J.M., \& Ohlin, J.B. (2004). The Application of Title III of the ADA to sport web sites. Journal of Legal Aspects of Sport, 14, 161-169.

Hardin, M., \& Hardin, B. (2004). The "supercrip" in sport media: Wheelchair athletes discuss hegemony's disabled hero. Sociology of Sport Online, 7(1), 1-16.

Howe, P.D. (2008). From inside the newsroom Paralympic media and the production of elite disability. International Review for the Sociology of Sport, 43(2), 135-150. doi:10.1177/1012690208095376

Jenkins, S.P., \& Rigg, J.A. (2004). Disability and disadvantage: Selection, onset, and duration effects. Journal of Social Policy, 33, 479-501. doi:10.1017/S0047279404007780

Johnson v. Florida High School Activities Association, 899 F.Supp. 579 (M. D. Fla. 1995).

Jongbloed, L., \& Crichton, A. (1990). Difficulties in shifting from individualistic to sociopolitical policy regarding disability in Canada. Disability, Handicap \& Society, 5(1), 25-36. doi:10.1080/02674649066780021 
Lincoln, Y., \& Guba, E.G. (1985). Naturalistic inquiry. Newbury Park, CA: Sage.

McClain, L., Medrano, D., Marcum, M., \& Schukar, J. (2000). A qualitative assessment of wheelchair users' experience with ADA compliance, physical barriers, and secondary health conditions. Topics in Spinal Cord Injury Rehabilitation, 6(1), 99-118. doi:10.1310/ENAP-Y4E7-RG05-6YV5

Mestayer, L., Black, J., Edwards, T., Behlmann, A., \& Cottingham, M. (2013). A case study: An examination of access for those with disabilities at revenue-generating sport facilities at an NCAA Institution. Journal of Facility Planning, Design, and Management, 1(1), 16-27.

Meyers, A.R., Anderson, J.J., Miller, D.R., Shipp, K., \& Hoenig, H. (2002). Barriers, facilitators, and access for wheelchair users: Substantive and methodologic lessons from a pilot study of environmental effects. Social Science \& Medicine, 55(8), 1435-1446. doi:10.1016/S0277-9536(01)00269-6

Moorman, A.M., \& Masteralexis, L.P. (2001). Writing an Amicus Curiae brief to the United States Supreme Court: The role of the disability sport community in interpreting the Americans with Disabilities Act. Journal of Legal Aspects of Sport, 11(3), 285-315.

Nelson, G. (2008). University reaches settlement in Big House lawsuit. The Michigan Daily. Retrieved October 8, 2015 from https://www.michigandaily.com/content/universityreaches-settlement-big-house-lawsuit.

Pappous, A., Marcellini, A., \& de Léséleuc, E. (2011). From Sydney to Beijing: The evolution of the photographic coverage of Paralympic Games in five European countries. Sport in society, 14(3), 345-354.

Paralyzed veterans of America, et al. v. D.C. Arena L.P., 117 F.3d 579 (D.C. Cir. 1997).

Patton, M.Q. (2002). Qualitative research \& evaluation methods (3rd ed.). Thousand Oaks, CA: Sage.

PGA Tour, Inc. v. Martin, 532 U.S. 661 (2001).

Rimmer, J.H. (2005). The conspicuous absence of people with disabilities in public fitness and recreation facilities: Lack of interest or lack of access? American Journal of Health Promotion, 19(5), 327-329. doi:10.4278/0890-1171-19.5.327

Rimmer, J.H., Riley, B., Wang, E., Rauworth, A., \& Jurkowski, J. (2004). Physical activity participation among persons with disabilities: Barriers and facilitators. American Journal of Preventive Medicine, 26(5), 419-425. doi:10.1016/j.amepre.2004.02.002

Stephens, C., Neil, R., \& Smith, P. (2012). The perceived benefits and barriers of sport in spinal cord injured individuals: A qualitative study. Disability and Rehabilitation, 34(24), 2061-2070. doi:10.3109/09638288.2012.669020

Strauss, A., \& Corbin, J. (1998). Basics of qualitative research: Techniques and procedures for developing grounded theory (2nd ed.). Thousand Oaks, CA: Sage.

Swartz, L., \& Watermeyer, B. (2008). Cyborg anxiety: Oscar Pistorius and the boundaries of what it means to be human. Disability \& Society, 23(2), 187-190. doi:10.1080/09687590701841232 